Book Review

\title{
STEM Leadership: How do I Create a STEM Culture in my School
}

Buckner, T., \& Boyd, B. (2015). STEM leadership: How do I create a STEM culture in my school? Alexandria, VA: ASCD. ISBN: 978-1-4166-2092-1 $\$ 12.99$. 46 pages.

As our world becomes a global society, educators must ensure students have the skills to succeed. Many of the skills students need to succeed focus on the science, technology, engineering, and mathematics (STEM) fields. Every school year brings new changes from staff to curriculum, and it can be hard as an administrator to decide what to prioritize or and specifically focus on for the school year. Buckner and Boyd's expertise in STEM education, along with their drive to provide educators a way of learning best practices in STEM, led to their creation of the book STEM Leadership: How do I Create a STEM Culture in my School? Buckner and Boyd do an outstanding job at describing how middle and high school administrators or school leaders can create a STEM culture in their building, and why it is important to do so.

\section{A Brief Synopsis}

Buckner and Boyd begin by focusing on what STEM education looks like, including how it entails meaningful learning experiences, real-world connections, and is available to all students. The authors emphasize throughout the book that STEM skills need to be taught to students beginning in kindergarten and continue through twelfth grade to ensure students have the opportunity to become STEM-literate. One of the key aspects of STEM education is that lessons should be rich and rigorous experiences for students. However, even if educators know the importance of STEM education, they often have reservations about implementing STEM-created lessons because of the extended amount of time it takes to plan and teach them.

Buckner and Boyd move on to discuss how further professional development is needed for in-service teachers to develop 21st Century learning skills and to build the STEM culture within their school. Educators will need to work together to establish and maintain a STEM culture; it cannot be accomplished or sustained by a sole individual. The authors recommend administrators or school leaders set aside time to meet and collaborate with each educator on staff per semester to begin creating a culture of collaboration, open dialogue, and trust. Buckner and Boyd also recommend creating a team of individuals who are on board with the implementation of STEM education to set the stage for STEM culture and what it will mean for school as a whole. It is important for administrators and school leaders to remember that not only is educator buy-in crucial, but so is educator respect. By educators working together to create a STEM culture at the school, they can begin to create 
curriculum, bring in outside connections, and ultimately enhance student learning with high-quality STEM instruction.

\section{Critical Analysis}

Overall, Buckner and Boyd do a terrific job at presenting ideas logically for easy implementation; they also provide a self-check rubric to help leaders evaluate how well they are creating a STEM culture through rich and rigorous learning experiences. Another helpful addition in the book is " 10 Key Questions to Assess Your Learners' $21^{\text {st }}$ Century Skills"; these questions allow administrators and staff to analyze the implementation of professional development techniques and critique what is working and what is not.

There were two areas of the text, in my opinion, that could have been expanded. First, the authors could have expanded on - especially with mentioning the need for STEM education throughout all grades - how to create a STEM culture at the elementary level. The ideas throughout the book are specifically written for middle and high schools, and thus exclude almost half of a student's education. If there is such a push for STEM education to be included in all grades, why would the authors exclude how to implement a STEM culture at the elementary level? Another area in which the authors could have expanded on is how educators individually can create a STEM culture within their classroom. The book is geared toward administrators or school leaders and how they can establish a STEM culture, but it does not detail how educators can begin the process themselves. There are situations when an administrator may not be on board with implementing STEM or even the possibility of working in a small school where such an undertaking is not feasible.

\section{Conclusion}

This fifty-two-page book is a quick, easy to read, and provides needed information for middle and high school administrators or school leaders who want to focus on creating a STEM culture in their school. A STEM culture consists of having a safe an open dialogue between all parties involved to share ideas, expand learning, and to create new opportunities for students. It is also necessary that all individuals involved, whether it is staff members, outside professionals, or students, understand the goals and expectations of the STEM culture being created. The creation of a STEM culture will not happen overnight, nor will it be an easy task. Administrators and school leaders are going to have to work alongside educators guiding and supporting them in what will be a challenging and time-consuming process.

Carlotta Vaughn (carlottavaughn@u.boisestate.edu) is an Elementary Teacher at Stephensen Elementary School in the Mountain Home School District \#193 in Mountain Home, Idaho, and a Doctoral Student at Boise State University in the Educational Technology Department. 